Received: 2014.01.21

Accepted: 2014.02.21

Published: 2014.06.11
Authors' Contribution:

Study Design A

Data Collection B

Statistical Analysis C

Data Interpretation D

Manuscript Preparation E

Literature Search F

Funds Collection G

\title{
Pulmonary function differences in patients with chronic right heart failure secondary to pulmonary arterial hypertension and chronic left heart failure
}

\author{
Wei-Hua Liu \\ Qin Luo \\ Zhi-Hong Liu \\ Qing Zhao \\ Qun-Ying Xi \\ Hai-Feng Xue \\ Zhi-Hui Zhao
}

State Key Laboratory of Cardiovascular Disease, Fuwai Hospital, National Center for Cardiovascular Diseases, Chinese Academy of Medical Sciences, Peking Union Medical College, Beijing, China

Background: Pulmonary abnormalities are found in both chronic heart failure (CHF) and pulmonary arterial hypertension (PAH). The differences of pulmonary function in chronic left heart failure and chronic right heart failure are not fully understood.

Material/Methods: We evaluated 120 patients with stable CHF (60 with chronic left heart failure and 60 with chronic right heart failure). All patients had pulmonary function testing, including pulmonary function testing at rest and incremental cardiopulmonary exercise testing (CPX).

Results: Patients with right heart failure had a significantly lower end-tidal partial pressure of $\mathrm{CO}_{2}\left(\mathrm{PetCO}_{2}\right)$, higher endtidal partial pressure of $\mathrm{O}_{2}\left(\mathrm{PetO}_{2}\right)$ and minute ventilation $/ \mathrm{CO}_{2}$ production $\left(\mathrm{VE} / \mathrm{VCO}_{2}\right)$ at rest. Patients with right heart failure had a lower peak PetCO ${ }_{2}$, and a higher peak dead space volume/tidal volume (VD/VT) ratio, peak $\mathrm{PetO}_{2}$, peak $\mathrm{VE} / \mathrm{VCO}_{2}$, and $\mathrm{VE} / \mathrm{VCO}_{2}$ slope during exercise. Patients with right heart failure had more changes in $\triangle \mathrm{PetCO}$ and $\triangle \mathrm{VE} / \mathrm{VCO}_{2}$, from rest to exercise.

Conclusions: Patients with right heart failure had worse pulmonary function at rest and exercise, which was due to severe ventilation/perfusion (V/Q) mismatching, severe ventilation inefficiency, and gas exchange abnormality.

MeSH Keywords: $\quad$ Coronary Disease - rehabilitation - Heart Failure - prevention \& control • Respiratory Function Tests - methods

Full-text PDF: http://www.medscimonit.com/download/index/idArt/890409

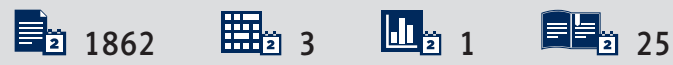




\section{Background}

There are symptoms common to both chronic heart failure (CHF) and pulmonary arterial hypertension (PAH). The heart, lungs, kidneys, and muscles are affected in both diseases. Pulmonary abnormalities play an important role in the evaluation and prognosis of CHF and $\mathrm{PAH}$. The differences of pulmonary function in chronic left heart failure and chronic right heart failure are not fully understood.

Cardiopulmonary exercise testing (CPX) is considered the criterion standard for studying cardiovascular, pulmonary, and metabolic adaptations to exercise in heart disease. Pulmonary abnormalities occur in both CHF and chronic right heart failure secondary to $\mathrm{PAH}$ [1-9]. Left heart failure with cardiac enlargement causes restrictive lung disease, interstitial edema, alveolar-capillary hydrostatic injury, and fatigue of respiratory muscles, which contributes to pulmonary abnormalities. PAH can cause ventilation/perfusion (V/Q) inequality secondary to pulmonary vascular bed damage. Hyperventilation may result from these pulmonary function changes.

We hypothesized that pulmonary function is different in patients with left heart failure and right heart failure secondary to PAH. This study may help understand relationships between pulmonary abnormalities and different types of heart failure.

\section{Material and Methods}

\section{Patients}

A single cardiologist evaluated 120 patients with clinically stable CHF, including 60 patients with chronic left heart failure and 60 patients with chronic right heart failure. Left heart failure was diagnosed using the American College of Cardiology Foundation (ACCF)/American Heart Association (AHA) guidelines for heart failure [10]. PAH was defined as WHO group1 $\mathrm{PH}$ according to the ACCF/AHA expert consensus document on pulmonary hypertension. We excluded patients with group $2,3,4$, or 5, associated with congenital heart disease, portal hypertension, significant venous or capillary involvement, or persistent pulmonary hypertension of the newborn [11]. Right heart failure was defined as PAH and cardiac index (CI) $<2.2 \mathrm{~L} /\left(\min \times \mathrm{m}^{2}\right)$ as measured by right heart catheterization. All patients had symptoms and/or signs of right heart failure. All patients had a forced expiratory volume in $1 \mathrm{~s} /$ forced vital capacity (FEV1/FVC) ratio $>65 \%$ at rest. All testing was performed before treatment.

The study protocol adhered to the Declaration of Helsinki. Each patient provided written informed consent to participate in this study. The document was approved and recorded by the institutional Ethics Committee of Fuwai Hospital, China. The project approval number was 2012-401.

\section{Pulmonary function test at rest}

Pulmonary function testing at rest was performed using a closed-circuit spirometer (COSMED, Italy) according to the American Thoracic Society (ATS) recommendations [12]. Dead space volume/tidal volume (VD/VT) $=\left(\mathrm{PaCO}_{2}-\mathrm{PECO}_{2}\right.$ mean $) /$ $\mathrm{PaCO}_{2}$ - [VD (machine)/VT] where $\mathrm{PaCO}_{2}=$ arterial $\mathrm{CO}_{2}$ tension, $\mathrm{PECO}_{2}=$ the partial pressure of expired $\mathrm{CO}_{2}$. Minute ventilation $/ \mathrm{CO}_{2}$ production $\left(\mathrm{VE} / \mathrm{VCO}_{2}\right.$ ) ratio was defined as $\mathrm{VE} / \mathrm{VCO}{ }_{2}$ $=863 /\left[\mathrm{PaCO}_{2} \times(1-\mathrm{VD} / \mathrm{VT})\right]$

\section{Cardiopulmonary exercise testing}

Physician-supervised CPX was performed on a bicycle ergometer with a breath-by-breath system (COSMED, Italy) according to the ATS/American College of Chest Physicians (ACCP) Statement on CPX [13]. Exercise-induced right-to-left shunt (EIS) was performed according to criteria described by Sun [14].

Breathing reserve $(B R)$ was defined as: $B R=(M V V-p e a k \mathrm{VE}) /$ $M V V \times 100 \%$ where MVV = maximal voluntary ventilation.

Change in CPX parameter from rest to peak exercise was defined as: $\Delta$ measure $=($ peak measure-rest measure $) /$ rest measure $\times 100 \%$.

\section{Echocardiography}

Two-dimensional echocardiography and Doppler ultrasound (Philips IE33, Netherlands) examinations were performed on the same day before CPX. Left ventricular ejection fraction (LVEF) was determined according to the recommendations of the European Association of Echocardiography [15].

\section{Right heart catheterization}

Right heart catheterization was performed 3 days after CPX. Pulmonary capillary wedge pressure (PCWP) and mean pulmonary artery pressure (MPAP) were determined with balloon flotation catheter (Edwards Lifesciences, USA). CI was determined by Frick method.

\section{Statistical analyses}

Data were analyzed using SPSS 13.0 (SPSS Inc; Chicago IL). Continuous variables are presented as mean \pm SD and categorical variables as a percentage. The $t$ test was used to compare continuous variables. The chi-square test was used to compare categorical variables. Multivariate linear regression was used to determine pulmonary function differences and the changes 
Table 1. Baseline characteristics.

\begin{tabular}{|c|c|c|c|}
\hline Characteristic & Left heart failure $(n=60)$ & Right heart failure $(n=60)$ & $P$ value \\
\hline Men, $\mathrm{n}$ & 53 & 10 & $<0.001$ \\
\hline Age, years & $45.1 \pm 9.9$ & $30.8 \pm 9.5$ & $<0.001$ \\
\hline $\mathrm{BMI}, \mathrm{kg} / \mathrm{m}^{2}$ & $24.12 \pm 3.94$ & $22.13 \pm 2.95$ & 0.002 \\
\hline Smokers, $\mathrm{n}$ & 37 & 4 & $<0.001$ \\
\hline NYHA, $n$ & & & 0.131 \\
\hline Class I/II & 18 & 27 & - \\
\hline Class III/IV & 42 & 33 & - \\
\hline LVEF,\% & $27.92 \pm 8.99$ & $64.65 \pm 6.31$ & $<0.001$ \\
\hline mPAP, $\mathrm{mmHg}$ & - & $54.35 \pm 16.91$ & - \\
\hline PCWP, $\mathrm{mmHg}$ & - & $9.20 \pm 3.83$ & - \\
\hline $\mathrm{Cl}, \mathrm{L} / \mathrm{min} \times \mathrm{m}^{2}$ & - & $1.99 \pm 0.22$ & - \\
\hline ICM, $\mathrm{n}$ & 13 & - & - \\
\hline NICM, $n$ & 47 & - & - \\
\hline $\mathrm{IPAH}, \mathrm{n}$ & - & 44 & - \\
\hline FPAH, $n$ & & 2 & \\
\hline $\mathrm{APAH}, \mathrm{n}$ & & 14 & \\
\hline
\end{tabular}

ICM - ischemic cardiomyopathy; NICM - non-ischemic cardiomyopathy; IPAH - idiopathic pulmonary arterial hypertension; $\mathrm{FPAH}$ - familial pulmonary arterial hypertension; APAH - associated with pulmonary arterial hypertension.

in CPX parameters between the 2 groups. To correct for demographic differences between the 2 groups of patients, variables that were either biologically plausible and/or significantly different between groups in univariate analysis were entered into the multivariate model. $P<0.05$ was considered statistically significant.

\section{Results}

Demographic data from the 2 patient groups are presented in Table 1. Patients with left heart failure were older, had a higher proportion of men and smokers, and had a higher BMI. These findings could affect pulmonary function.

The anaerobic threshold (AT) was detectable in all patients. Among the patients with right heart failure, 21 showed EIS. Table 2 shows the results of univariate analysis of pulmonary function. Patients with right heart failure had lower oxygen uptake $\left(\mathrm{VO}_{2}\right)$, VT, FEV1, FVC, MVV, and PetCO, and higher end-tidal partial pressure of $\mathrm{O}_{2}\left(\mathrm{PetO}_{2}\right)$ and $\mathrm{VE} / \mathrm{VCO}_{2}$ at rest. Right heart failure patients had lower peak $\mathrm{VO}_{2}$, peak VE, peak VT, and peak PetCO, and had higher peak VD/VT, peak PetO ${ }_{2}$, peak VE/VCO ${ }_{2}$, and $\mathrm{VE} / \mathrm{VCO}_{2}$ slope during exercise. Right heart failure patients had lower $\Delta \mathrm{VO}_{2}, \Delta \mathrm{VE}, \Delta \mathrm{PetCO}$, and $\triangle \mathrm{VE} / \mathrm{VCO}_{2}$, from rest to exercise.

Table 3 shows the result of multivariate regression analysis of pulmonary function. Patients with right heart failure had lower
PetCO ${ }_{2}$, and higher PetO $\mathrm{O}_{2}$ and VE/ $\mathrm{VCO}_{2}$ at rest. Right heart failure patients had a lower peak PetCO ${ }_{2}$, and higher peak VD/VT, peak PetO ${ }_{2}$, peak VE/VCO ${ }_{2}$, and $\mathrm{VE} / \mathrm{VCO}_{2}$ slope during exercise. Right heart failure patients had lower $\triangle \mathrm{PetCO}$, and $\triangle \mathrm{VE} / \mathrm{VCO}_{2}$, from rest to exercise.

Figure $1 \mathrm{~A}$ shows the result of VD/VT ratio versus $\mathrm{VE} / \mathrm{VCO}_{2}$ at rest. The curves show patients with right heart failure had higher VE/VCO 2 and lower PetCO 2 at any given VD/VT ratio at rest. Figure $1 \mathrm{~B}$ shows the result of peak $\mathrm{PetCO}$, versus VE/VCO slope. The abrupt curve of right heart failure was suggestive of EIS in the right heart failure patients during exercise. Most right heart failure patients had higher VE/VCO slope and peak VD/VT at any given peak PetCO ${ }_{2}$. Figure $1 \mathrm{C}$ shows the result of peak VD/VT ratio versus VE/ $\mathrm{VCO}_{2}$ slope. The curves show that most right heart failure patients had a lower PetCO $\mathrm{C}_{2}$ and higher VD/VT ratio at any given.

\section{Discussion}

Patients with right heart failure had lower PetCO ${ }_{2}$, and higher PetO $\mathrm{O}_{2}$ and $\mathrm{VE} / \mathrm{VCO}_{2}$ at rest. Patients with right heart failure showed a higher peak VD/VT, peak PetO ${ }_{2}$, peak VE/VCO $\mathrm{CO}_{2}$, and $\mathrm{VE} / \mathrm{VCO}_{2}$ slope, and a lower PetCO $\mathrm{C}_{2}$ during exercise. Patients with right heart failure had more changes in $\triangle \mathrm{PetCO}_{2}$ and $\triangle \mathrm{VE} /$ $\mathrm{VCO}_{2}$ from rest to exercise. These results show that patients 
Table 2. Univariate analysis of pulmonary function.

\begin{tabular}{|c|c|c|c|}
\hline Measure & Left heart failure & Right heart failure & P valure \\
\hline Rest $\mathrm{VO}_{2}, \mathrm{ml} / \mathrm{min}$ & $341.82 \pm 97.65$ & $285.07 \pm 67.69$ & $<0.001$ \\
\hline Rest VE, L/min & $11.09 \pm 3.16$ & $10.42 \pm 2.75$ & 0.214 \\
\hline Rest VT, L & $0.68 \pm 0.20$ & $0.59 \pm 0.22$ & 0.028 \\
\hline Rest FEV1, L & $2.89 \pm 0.57$ & $2.55 \pm 0.59$ & 0.001 \\
\hline Rest FVC, L & $3.69 \pm 0.69$ & $3.23 \pm 0.74$ & 0.001 \\
\hline Rest FEV1/FVC, \% & $79.28 \pm 5.41$ & $79.25 \pm 7.70$ & 0.984 \\
\hline Rest MVV, L/min & $118.27 \pm 28.62$ & $97.17 \pm 27.12$ & $<0.001$ \\
\hline Rest Rf, b/min & $17.02 \pm 4.69$ & $18.82 \pm 5.44$ & 0.054 \\
\hline Rest VD/VT, \% & $31.40 \pm 5.62$ & $31.67 \pm 4.69$ & 0.778 \\
\hline Rest $\mathrm{PetCO}_{2}, \mathrm{mmHg}$ & $33.72 \pm 4.47$ & $28.78 \pm 4.25$ & $<0.001$ \\
\hline Rest PetO ${ }_{2}, \mathrm{mmHg}$ & $110.68 \pm 7.48$ & $115.80 \pm 6.65$ & $<0.001$ \\
\hline Rest VE $/ \mathrm{VCO}_{2}, \mathrm{~L} / \mathrm{min} / \mathrm{L} / \mathrm{min}$ & $37.96 \pm 6.50$ & $43.45 \pm 6.79$ & $<0.001$ \\
\hline Peak $\mathrm{VO}_{2}, \mathrm{ml} / \mathrm{min}$ & $1092.85 \pm 309.73$ & $756.83 \pm 271.30$ & $<0.001$ \\
\hline Peak VE, L/min & $43.62 \pm 11.79$ & $36.91 \pm 14.71$ & 0.007 \\
\hline Peak BR, \% & $61.80 \pm 9.77$ & $63.83 \pm 12.19$ & 0.315 \\
\hline Peak VT, L & $1.47 \pm 0.41$ & $1.19 \pm 0.36$ & $<0.001$ \\
\hline Peak Rf, b/min & $30.30 \pm 6.01$ & $31.24 \pm 8.04$ & 0.468 \\
\hline Peak VD/VT, \% & $27.18 \pm 4.02$ & $28.83 \pm 4.04$ & 0.027 \\
\hline Peak PetCO ${ }_{2}, \mathrm{mmHg}$ & $33.42 \pm 6.04$ & $24.32 \pm 5.30$ & $<0.001$ \\
\hline Peak PetO ${ }_{2} \mathrm{mmHg}$ & $117.17 \pm 6.10$ & $124.43 \pm 5.61$ & $<0.001$ \\
\hline Peak VE $/ \mathrm{VCO}_{2}, \mathrm{~L} / \mathrm{min} / \mathrm{L} / \mathrm{min}$, & $36.13 \pm 7.97$ & $48.50 \pm 11.95$ & $<0.001$ \\
\hline VE/ $\mathrm{VCO}_{2}$ slope & $32.74 \pm 7.52$ & $45.70 \pm 16.18$ & 0.001 \\
\hline EIS, $n$ & - & 21 & \\
\hline$\Delta \mathrm{VO}_{2}, \%$ & $236.40 \pm 108.37$ & $171.28 \pm 82.76$ & $<0.001$ \\
\hline$\Delta \mathrm{VE}, \%$ & $323.56 \pm 168.47$ & $262.41 \pm 118.19$ & 0.023 \\
\hline$\Delta \mathrm{VT}, \%$ & $126.49 \pm 59.07$ & $114.34 \pm 68.37$ & 0.300 \\
\hline$\Delta \mathrm{Rf}, \%$ & $88.70 \pm 58.52$ & $72.89 \pm 45.66$ & 0.054 \\
\hline$\Delta \mathrm{VD} / \mathrm{VT}, \%$ & $-11.71 \pm 15.45$ & $-7.72 \pm 14.21$ & 0.300 \\
\hline$\triangle \mathrm{PetCO}_{2}, \%$ & $-0.61 \pm 14.16$ & $-15.61 \pm 12.91$ & $<0.001$ \\
\hline$\Delta$ PetO $_{2}, \%$ & $6.18 \pm 7.06$ & $7.65 \pm 5.12$ & 0.196 \\
\hline$\Delta \mathrm{VE} / \mathrm{VCO}_{2}, \%$ & $4.55 \pm 16.28$ & $-11.46 \pm 18.68$ & $<0.001$ \\
\hline
\end{tabular}

$\mathrm{Rf}$ - respiratory frequency.

with right heart failure had worse pulmonary function at rest and exercise.

\section{Pulmonary function at rest}

Pulmonary function changes compatible with restrictive lung disease are observed in most patients with severe CHF $[16,17]$, and findings compatible with airway obstruction are common in patients with right heart failure caused by idiopathic pulmonary arterial hypertension (IPAH) [18]. We did not observed any different ventilatory measures at rest in the 2 groups.

PetCO ${ }_{2}$ reflects ventricular function [19]. Right heart failure patients had a lower PetCO $_{2}$ (Table 3, Figure 1A). Figure $1 \mathrm{~A}$ 
Table 3. Multivariate regression analysis of pulmonary function.

\begin{tabular}{|c|c|c|}
\hline Measure & $\beta$ & P value \\
\hline Rest $\mathrm{VO}_{2}, \mathrm{ml} / \mathrm{min}$ & -0.052 & 0.700 \\
\hline Rest VT, L & 0.058 & 0.687 \\
\hline Rest FEV1, L & -0.139 & 0.304 \\
\hline Rest FVC, L & -0.004 & 0.977 \\
\hline Rest MVV, L/min & -0.049 & 0.705 \\
\hline Rest Rf, b/min & 0.064 & 0.664 \\
\hline Rest PetCO, $\mathrm{mmHg}$ & -0.435 & 0.001 \\
\hline Rest PetO, $\mathrm{mmHg}$ & 0.329 & 0.023 \\
\hline Rest VE/VCO ${ }_{2}, \mathrm{~L} / \mathrm{min} / \mathrm{L} / \mathrm{min}$ & 0.320 & 0.020 \\
\hline Peak $\mathrm{VO}_{2}, \mathrm{ml} / \mathrm{min}$ & -0.174 & 0.118 \\
\hline Peak VE, L/min & 0.213 & 0.102 \\
\hline Peak VT, L & 0.179 & 0.149 \\
\hline Peak VD/VT,\% & 0.376 & 0.010 \\
\hline Peak PetCO ${ }_{2}, \mathrm{mmHg}$ & -0.704 & $<0.001$ \\
\hline Peak PetO ${ }_{2}, \mathrm{mmHg}$ & 0.655 & $<0.001$ \\
\hline Peak VE $/ \mathrm{VCO}_{2}, \mathrm{~L} / \mathrm{min} / \mathrm{L} / \mathrm{min}$, & 0.614 & $<0.001$ \\
\hline VE/VCO ${ }_{2}$ slope & 0.506 & 0.001 \\
\hline$\Delta \mathrm{VO}^{2}, \%$ & -0.195 & 0.171 \\
\hline$\Delta \mathrm{VE}, \%$ & 0.003 & 0.984 \\
\hline$\Delta \mathrm{Rf}, \%$ & -0.081 & 0.591 \\
\hline$\Delta \mathrm{PetCO}_{2}, \%$ & -0.657 & $<0.001$ \\
\hline$\Delta \mathrm{VE} / \mathrm{VCO}_{2}, \%$ & -0.622 & $<0.001$ \\
\hline
\end{tabular}

Left heart failure $=0$, right heart failure $=1$, female $=0$, male $=1$, non-smoker $=0$, smoker $=1$.

shows that right heart failure patients had a lower PetCO at any given VD/VT. These results demonstrate that patients with right heart failure had more ventilation at given $\mathrm{CO}_{2}$ discharge. Considering there was no difference in respiratory frequency or VE, the lower PetCO $\mathrm{C}_{2}$ was due to hyperventilation in alveolus with well-perfusion and hypoperfusion of well ventilated alveolus in patients with right heart failure $[20,21]$. The lower PetCO $\mathrm{C}_{2}$ could explain the higher VE/VCO ${ }_{2}$ in patients with right heart failure. The higher VE/VCO ${ }_{2}$ showed that right heart failure patients had lower ventilation efficiency. The higher $\mathrm{PetO}_{2}$ was a secondary effect of lower PetCO .

The VD/VT ratio reflects the V/Q mismatching [20]. There was no difference in VD/VT ratio between the 2 groups. This result means that there was no difference in $\mathrm{V} / \mathrm{Q}$ mismatching at rest in the 2 groups.

\section{Pulmonary function during exercise}

PetCO 2 was lower in both $\mathrm{CHF}$ and $\mathrm{PAH}$, reflecting the ventilation impairment [3,8,20-25]. We found that right heart failure patients had a lower PetCO during exercise (Table 3). The reason for the lower peak PetCO ${ }_{2}$ during exercise in patients with right heart failure was similar to the reason for lower $\mathrm{PetCO}_{2}$ at rest. Sun et al. [14] found that patients with PAH had an EIS resulting in abrupt decreased $\mathrm{PetCO}_{2}$, had increased $\mathrm{PetO}_{2}$, and increased $\mathrm{VE} / \mathrm{VCO}_{2}$ ratio during exercise. The abrupt curve of right heart failure demonstrated that patients with right heart failure had EIS (Figure 1B). EIS also contributed to the lower peak PetCO.

We found that patients with right heart failure had significantly higher peak VD/VT ratio (Table 3). Figure 1C shows that most patients with right heart failure had a lower peak PetCO $\mathrm{C}_{2}$ and a higher $\mathrm{VE} / \mathrm{VCO}_{2}$ slope. These results demonstrate that patients with right heart failure had severe V/Q mismatching at peak exercise. This means that primary pulmonary vesicular damage played a greater role in V/Q mismatching during exercise than did pulmonary congestion. Moreover, the EIS was involved in the higher VD/VT in patients with right heart failure.

$\mathrm{VE} / \mathrm{VCO}_{2}$ and $\mathrm{VE} / \mathrm{VCO}_{2}$ slope are important to reflect disease severity and prognosis in $\mathrm{CHF}$ and $\mathrm{PAH}$, and reflect $\mathrm{V} / \mathrm{Q}$ mismatching in $\mathrm{PAH}[21,25]$. We found that peak $\mathrm{VE} / \mathrm{VCO}_{2}$ and $\mathrm{VE} / \mathrm{VCO}_{2}$ slope were higher in patients with right heart failure. These results demonstrate that patients with right heart failure had more severe ventilation inefficiency and gas exchange abnormality compared to patients with left heart failure. These results were due to lower peak $\mathrm{PetCO}_{2}$ and higher peak VD/VT in right heart failure patients.

\section{Change in CPX parameters from rest to peak exercise}

We found that patients with right heart failure had higher absolute values of $\triangle \mathrm{PetCO}$ and $\triangle \mathrm{VE} / \mathrm{VCO}_{2}$ from rest to peak exercise (Table 2 and 3 ). These results show that right heart failure patients had larger changes of pulmonary function from rest to exercise. The larger change of $\Delta \mathrm{PetCO}_{2}$ demonstrates that patients with right heart failure had more severe hyperventilation from rest to exercise. This should be attributed to more complex ventilation drive in PAH, including exercise-induced hypoxia and EIS [20].

We found that patients with right heart failure had worse ventilation efficiency, severe V/Q mismatching, and gas exchange abnormality, even without differences in peak $\mathrm{VO}_{2}$.

This study had some limitations. It was a single-center study and demographic differences were detected between the 2 groups. The etiology of heart failure in the 2 groups resulted in differences of sex and age. Because there was no control group, we could not confirm a normal breathing pattern 


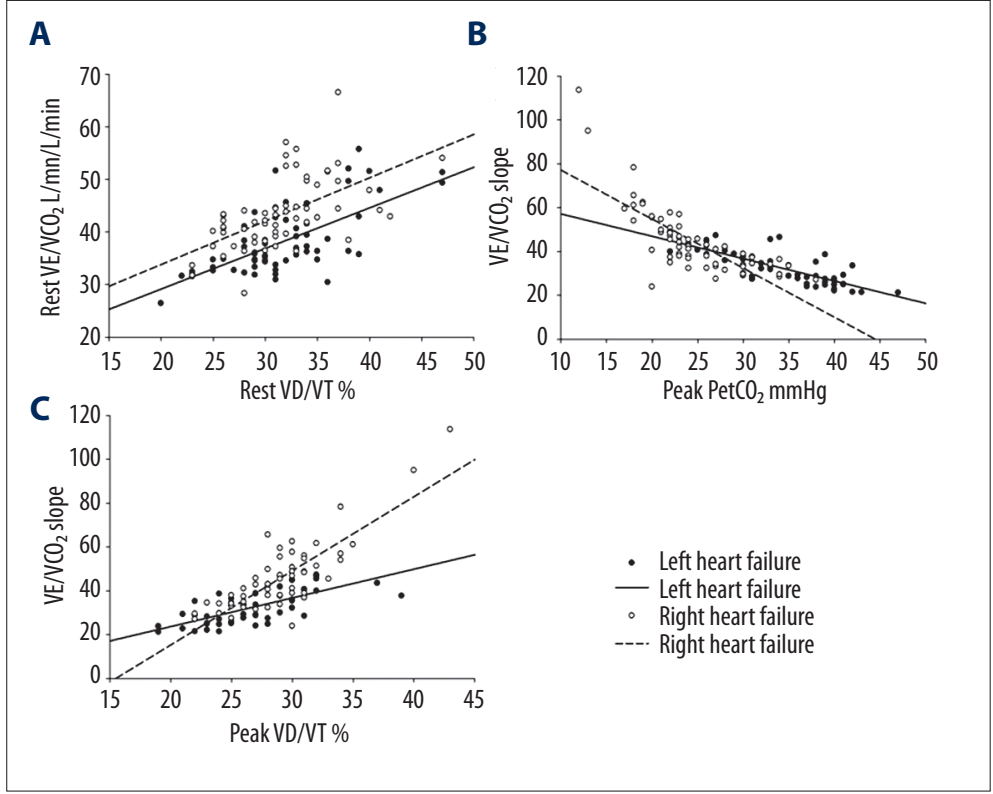

Figure 1. (A) VD/VT ratio versus VE/VCO at rest. The curves showed that patients with right heart failure had a higher $\mathrm{VE} / \mathrm{VCO}_{2}$ at any given VD/VT ratio at rest. (B) Peak PetCO 2 versus VE/VCO slope. The abrupt curve of right heart failure was suggestive of EIS in the right heart failure patients during exercise. (C) Peak VD/VT ratio versus $\mathrm{VE} / \mathrm{VCO}_{2}$ slope. The curves showed that most right heart failure patients had a lower $\mathrm{PetCO}_{2}$ at any given VD/ VT ratio.

at rest. We could not obtain diffusion function measures from all patients. This influenced the evaluation of pulmonary function. We could not perform invasive hemodynamic testing in all patients, which influenced our evaluation of left heart failure. We merged the 4 disease classes into 2 groups because there were not enough patients with class IV NYHA right heart failure.

\section{Conclusions}

Patients with right heart failure had worse pulmonary function at rest and during exercise. The differences in pulmonary

\section{References:}

1 Wright RS, Levine MS, Bellamy PE et al: Ventilatory and diffusion abnormalities in potential heart transplant recipients. Chest, 1990; 98(4): 816-20

2 Agostoni P, Cattadori G, Guazzi M et al: Cardiomegaly as a possible cause of lung dysfunction in patients with heart failure. Am Heart J, 2000; 140: e24

3 Wasserman K, Zhang YY, Gitt A et al. Lung function and exercise gas exchange in chronic heart failure. Circulation, 1997; 96(7): 2221-27

4 Papazachou O, Anastasiou-Nana M, Sakellariou D et al: Pulmonary function at peak exercise in patients with chronic heart failure. Int J Cardiol, 2007; 118(1): 28-35

5 De Feo S, Franceschini L, Brighetti G et al: Ischemic etiology of heart failure identifies patients with more severely impaired exercise capacity. Ischemic etiology of heart failure identifies patients with more severely impaired exercise capacity. Int J Cardiol, 2005; 104(3): 292-97

6 Ferrazza AM, Martolini D, Valli G, Palange P: Cardiopulmonary exercise testing in the functional and prognostic evaluation of patients with pulmonary diseases. Respiration, 2009; 77: 3-17

7 D'Alonzo GE, Gianotti LA, Pohil RL et al: Comparison of progressive exercise performance of normal subjects and patients with primary pulmonary hypertension. Chest, 1987; 92(1): 57-62

8 Arena R, Lavie CJ, Milani RV et al: Cardiopulmonary exercise testing in patients with pulmonary arterial hypertension: an evidence-based review. Heart Lung Transplant, 2010; 29(2): 159-73 function at rest were due to different breathing patterns and worse gas exchange in patients with right heart failure. The differences during exercise were due to severe V/Q mismatching, EIS, alveolar ventilation disorder, and oxygenation dysfunction secondary to pulmonary vascular damage in patients with right heart failure.

\section{Acknowledgments}

We thank Xiu-Ping, MA for excellent work in data collection.

9 Reybrouck T, Mertens L, Schulze-Neick I et al: Ventilatory inefficiency for carbon dioxide during exercise in patients with pulmonary hypertension. Clin Physiol, 1998; 18: 337-44

10 Jessup M, Abraham WT, Casey DE et al: 2009 focused update: ACCF/AHA Guidelines for the Diagnosis and Management of Heart Failure in Adults: a report of the American College of Cardiology Foundation/American Heart Association Task Force on Practice Guidelines: developed in collaboration with the International Society for Heart and Lung Transplantation. Circulation 2009; 119(14): 1977-2016

11 McLaughlin VV, Archer SL, Badesch DB et al: ACCF/AHA 2009 expert consensus document on pulmonary hypertension: a report of the American College of Cardiology Foundation Task Force on Expert Consensus Documents and the American Heart Association: developed in collaboration with the American College of Chest Physicians, American Thoracic Society, Inc., and the Pulmonary Hypertension Association. Circulation, 2009; 119: 2250-94

12 American Thoracic Society. Standardization of Spirometry, 1994 Update. Am J Respir Crit Care Med, 1995; 152: 1107-36

13 American Thoracic Society; American College of Chest Physicians. ATS/ACCP Statement on cardiopulmonary exercise testing. Am J RespirCrit Care Med, 2003; 167(2): 211-77

14 Sun XG, Hansen JE, Oudiz RJ, Wasserman K: Gas exchange detection of exercise-induced right-to-left shunt in patients with primary pulmonary hy pertension. Circulation, 2002; 105(1): 54-60 
15 Lang RM, Bierig M, Devereux RB et al: Recommendations for chamber quantification: a report from the American Society of Echocardiography's Guidelines and Standards Committee and the Chamber Quantification Writing Group, developed in conjunction with the European Association of Echocardiography, a branch of the European Society of Cardiology. J Am Soc Echocardiogr, 2005; 18: 1440-63

16 Agostoni P, Bussotti M, Cattadori G et al: Gas diffusion and alveolar-capillary unit in chronic heart failure. Eur Heart J, 2006; 27: 2538-43

17 Olson TP, Beck KC, Johnson BD: Pulmonary function changes associated with cardiomegaly in chronic heart failure. J Card Fail, 2007; 13: 100-7

18 Jing ZC, Xu XQ, Badesch DB et al: Pulmonary function testing in patients with pulmonary arterial hypertension. Respir Med, 2009; 103(8): 1136-42

19 Yano T, Yunoki T, Matsuura R, Arimitsu T: Relationship between hyperventilation and excessive $\mathrm{CO} 2$ output during recovery from repeated cycling sprints. Physiol Res, 2009; 58: 529-35

20 Wasserman K, Hansen J, Sue D et al: Priniciples of Exercise Testing and Interpretation. Lippincott Williams \& Wilkins, 2004; 80-145
21 Ting H, Sun XG, Chuang ML et al: A noninvasive assessment of pulmonary perfusion abnormality in patients with primary pulmonary hypertension. Chest, 2001; 119: 824-32

22 Matsumoto $\mathrm{A}$, Itoh $\mathrm{H}$, Eto $\mathrm{Y}$ et al: End-tidal $\mathrm{CO} 2$ pressure decreases during exercise in cardiac patients: association with severity of heart failure and cardiac output reserve. J Am Coll Cardiol, 2000; 36: 242-49

23 Myers J, Gujja P, Neelagaru S et al: End-tidal CO2 pressure and cardiac performance during exercise in heart failure. Med Sci Sports Exerc, 2009; 41: $19-25$

24 Dimopoulos S, Anastasiou-Nana M, Katsaros F et al: Impairment of autonomic nervous system activity in patients with pulmonary arterial hypertension: a case control study. J Card Fail, 2009; 15(10): 882-89

25 Guazzi M, Adams V, Conraads V et al: EACPR/AHA Scientific Statement. Clinical recommendations for cardiopulmonary exercise testing data assessment in specific patient populations. Circulation, 2012; 126: 2261-74 